\title{
THICKNESS DEPENDENCE OF MICROSTRUCTURE IN THIN CHROMIUM FILMS
}

\author{
Shiva L. $\mathbf{U}^{1}$, N.H.Ayachit ${ }^{2}$, Udachan L. $A^{3}$, Santoshkumar M Sunagar ${ }^{4}$ \\ ${ }^{1}$ Department of Physics, Rani Channamma University, Belagavi-591 156, Karnataka, India \\ ${ }^{2}$ Department of Physics, Rani Channamma University, Belagavi-591 156, Karnataka, India \\ ${ }^{3}$ Channabasaveshwar Arts, Science \& Commerce College, Bhalki, Dist:Bidar, Karnataka. \\ ${ }^{4}$ Government First Grade College, Yelahanka, Bangalore, Karnataka
}

\begin{abstract}
The microstructure of thin films is often dictated by the environment during the film formation, and the substrate orientation with respect to the target, the nature of depositing the material, substrate material and film thickness. Therefore this paper deals with the thickness dependence of microstructure in thin chromium films. The experimental methods of preparation of chromium films is by thermal evaporation in vacuum. Thin chromium films in the thickness range 100-800 $A^{0}$ have been grown on cleaned glass substrates at a rate of $5 \mathrm{~A}^{\circ} \mathrm{s}$, under a pressure of $\sim 10^{-6}$ Torr at room temperature of $22^{\circ} \mathrm{C}$. After this the films were taken out of the vacuum chamber for structural, topographical and morphological analysis using Transmission Electron Microscope(TEM), Atomic force microscope(AFM), Scanning Electron Microscope (SEM) and Energy Dispersive Spectroscopy (EDS) studies. It is noticed that the chromium islands are surrounded by a thin skin of oxide, which indicates the behavior of discontinuous films. The island size and the impurity content are strongly depend on the deposition parameters.
\end{abstract}

Keywords: Thin chromium films, Microstructure, Microscope.

\section{INTRODUCTION}

Chromium was amongst the first metals to be investigated as a thin film resistor material and is being used as an underlayer to provide a good adherence for other films in many electronic devices. It is not only used in electronic industry but also in optical appliances as a semi- reflection coating. In addition, chromium films are employed in the fabrication of semiconducting devices. Chromium in the bulk form exhibits anti- ferromagnetism with a Neel temperature of $308 \mathrm{~K}$, in addition to some interesting properties such as high resistivity, low temperature coefficient of resistance(TCR), high vapour pressure, high melting point, excellent chemical stability, good adherence and positive thermo-electric power(TEP).Because of the said interesting properties in the bulk form, we have decided to study the thickness dependence of microstructures by four different routes, namely TEM, AFM, SEM and EDS.

The deposition parameters includes, deposition rate ${ }^{1}$, substrate material,substrate temperature ${ }^{2}$, orientation of substrate $^{3}$ with respect to evaporation source, etc, influence very strongly the properties of metal coating ${ }^{4}$ especially the microstructure of chromium films ${ }^{5,6}$.

\section{EXPERIMENTAL SECTION}

The vacuum coating unit used in the present investigation is the 'Hind High Vacuum Coating Unit, Model 12A4D', to grow thin films of chromium in this work. The film thickness was controlled by means of an in-built Quartz Crystal Digital Thickness Monitor (Model DTM-101). Chromium was evaporated from a tungsten basket, and the distance between the basket and the glass substrate was around $\sim 22 \mathrm{~cm}$. Chromium of purity $99.999 \%$ was thermally evaporated by resistive heating technique on to cleaned glass slides. The glass slides were cleaned initially in chromic acid, ultrasonically and at last by the ionic bombardment method ${ }^{1,2}$. Thin chromium films in the thickness range $100-800 \mathrm{~A}^{0}$ have been grown on to thus cleaned glass substrates at the rate of $5 \mathrm{~A}^{0} \%$ under a pressure of $\sim 10^{-6}$ Torr at room temperature of $22^{\circ} \mathrm{C}$. After growing the films, the films were taken out of the vacuum chamber for microstructural \&Energy Dispersive Spectroscopy (EDS) analysis. The sample preparation for various microscopic studies, is given below.

(a) For TEM :Chromium films were grown in the conventional vacuum chamber on freshly cleaved mica substrates for their structural studies. The films were then peeled off from the mica substrates by immersing them in distilled water. Afterwards, these films were mounted on carbon coated copper grids(having 200 meshes $/ \mathrm{cm}^{2}$ ). All the films were examined with Hitachi Transmission Electron Microscope for bright field image.

(b) For AFM :A small sample holder will be provided with the AFM machine in which the sample can be cut and then stick to the sample holder, it will be less than $1 \mathrm{~cm}^{2}$ area.

(c) For SEM :In case of SEM analysis, for study of microstructure a sample of suitable size is taken. It is ground and polished and then etched using suitable etchant. The procedure in this case is similar to that of optical metallography ${ }^{7}$. 
(d) For EDS: Backscattered electron images in the SEM display compositional contrast that results from different atomic number elements and their distribution. Energy Dispersive Spectroscopy (EDS) allows one to identify what those particular elements are and their relative proportions (Atomic \% for example). Initial EDS analysis usually involves the generation of an X-ray spectrum from the entire scan area of the SEM.

\section{RESULTS AND DISCUSSION}

It is found that, grains consist of relatively pure islands of a metal in a matrix of insulating chromium oxide ${ }^{8}$ as shown in the TEM pictures figure 1.(a) $100 \mathrm{~A}^{0}$, (b) $400 \mathrm{~A}^{0} \&$ (c) $500 \mathrm{~A}^{0}$ for different magnifications. It is suggested that very thin films exhibit granular structure rather than a continuous structure ${ }^{9}$.
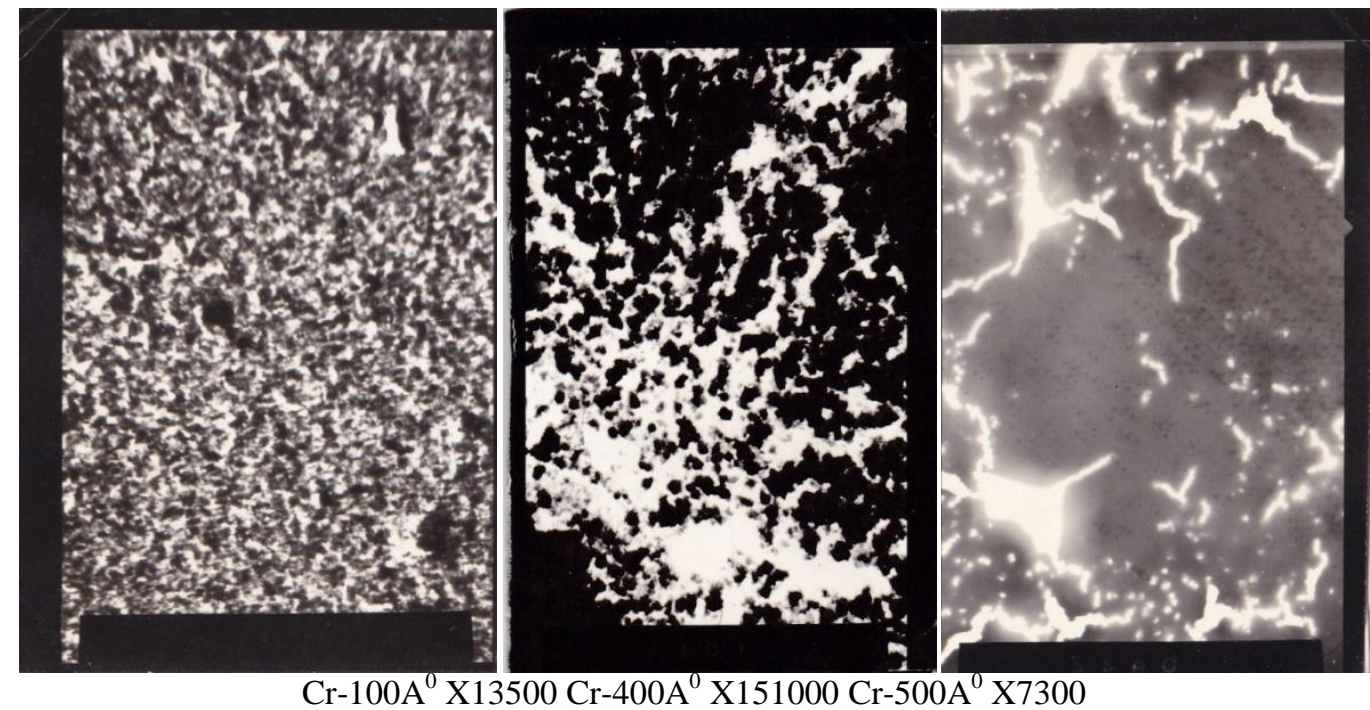

Fig.1. TEM PicturesChromium films, (a) $100 \mathrm{~A}^{0} \mathrm{X} 13500$, (b) $400 \mathrm{~A}^{0} \mathrm{X} 151000$, (c) $500 \mathrm{~A}^{0} \mathrm{X} 7300$.

As the deposition increases the islands grow bigger in size similar to columnar shape. from island structure, which is a three-dimensional picture and has been shown for chromium films of thicknesses $100 \mathrm{~A}^{0}, 200 \mathrm{~A}^{0}, 400 \mathrm{~A}^{0}, 600 \mathrm{~A}^{0}$ and $800 \mathrm{~A}^{0}$ in Figure2(a), (b), (c), (d) \& (e), respectively, along with their topography graph. Similar type of results were obtained by $\mathrm{T}$ M Rajkumar et.al. for $\mathrm{Cd}$ chalcogenide films[10].It is clear from the AFM Pictures as the thickness increases, from 100 to $600 \mathrm{~A}^{0}$, the roughness of the surface decreases and becoming almost a smooth surface. After this thickness we notice that there is a slight variation in the roughness.

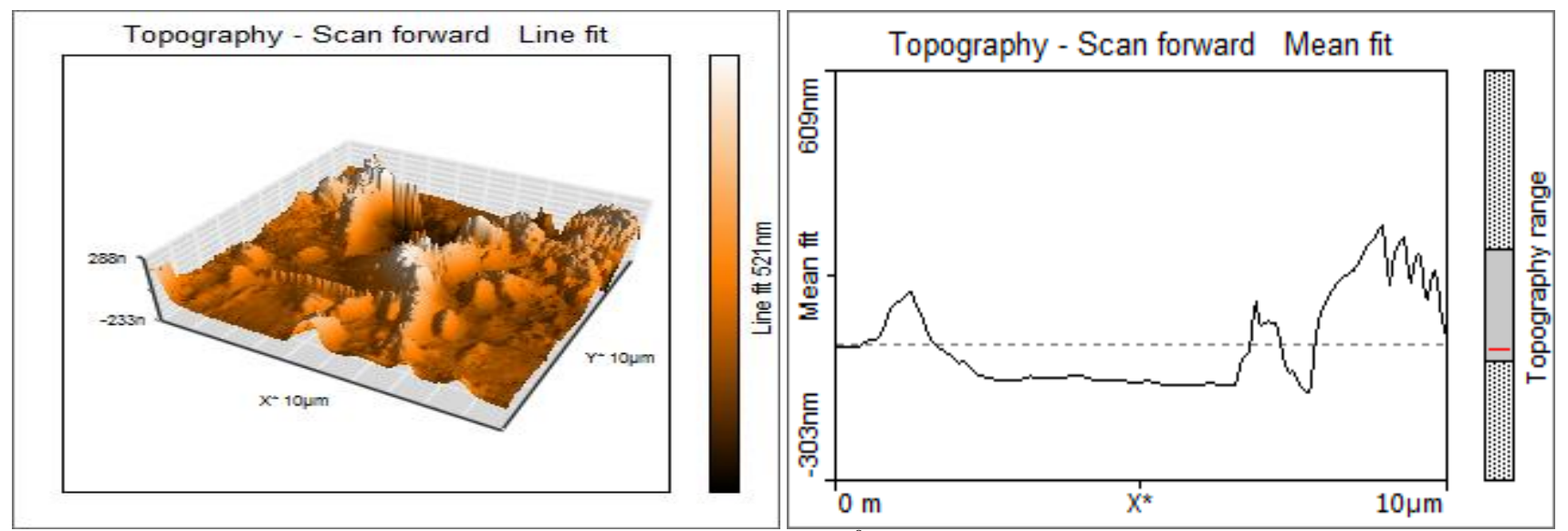

(a)Cr-100 $\mathrm{A}^{0}$ 


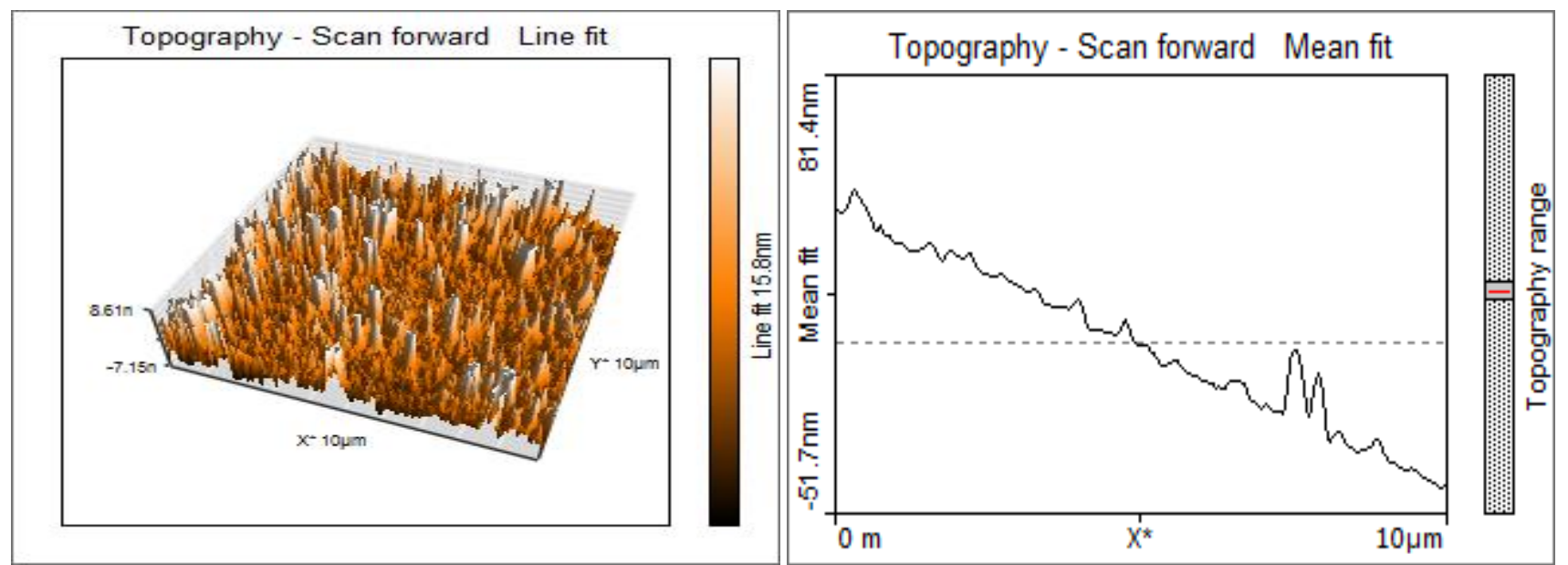

(b) $\mathrm{Cr}-200 \mathrm{~A}^{0}$

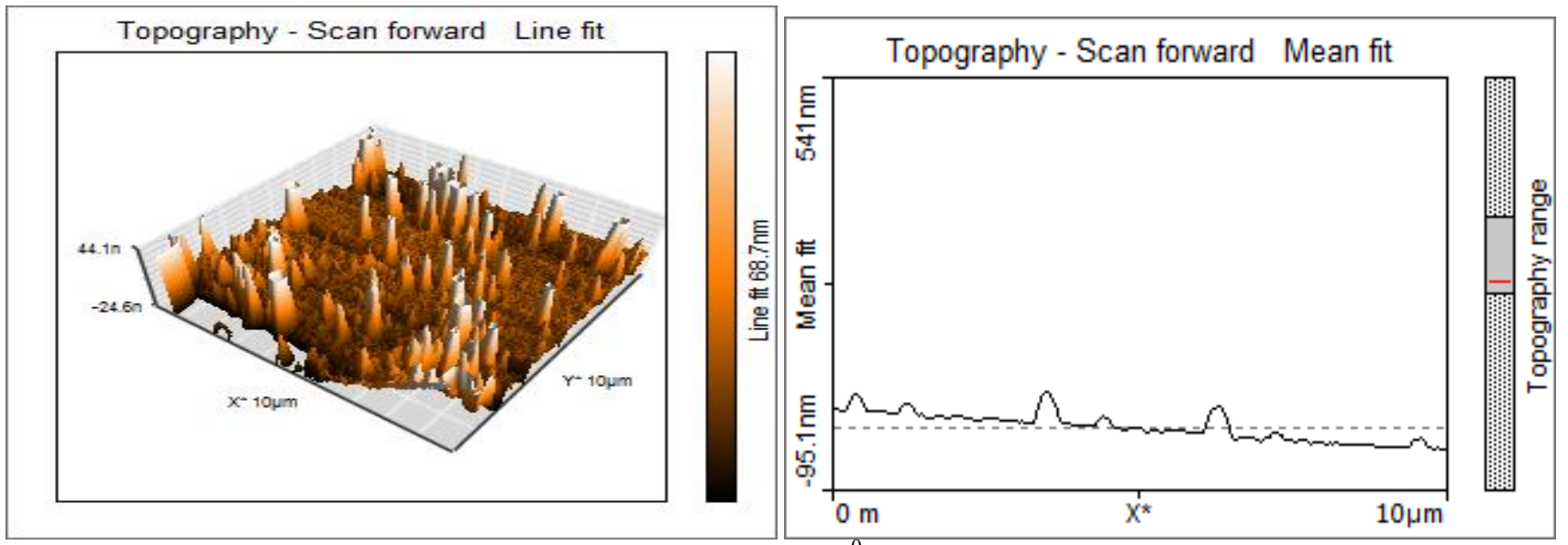

(c) $\mathrm{Cr}-400 \mathrm{~A}^{0}$

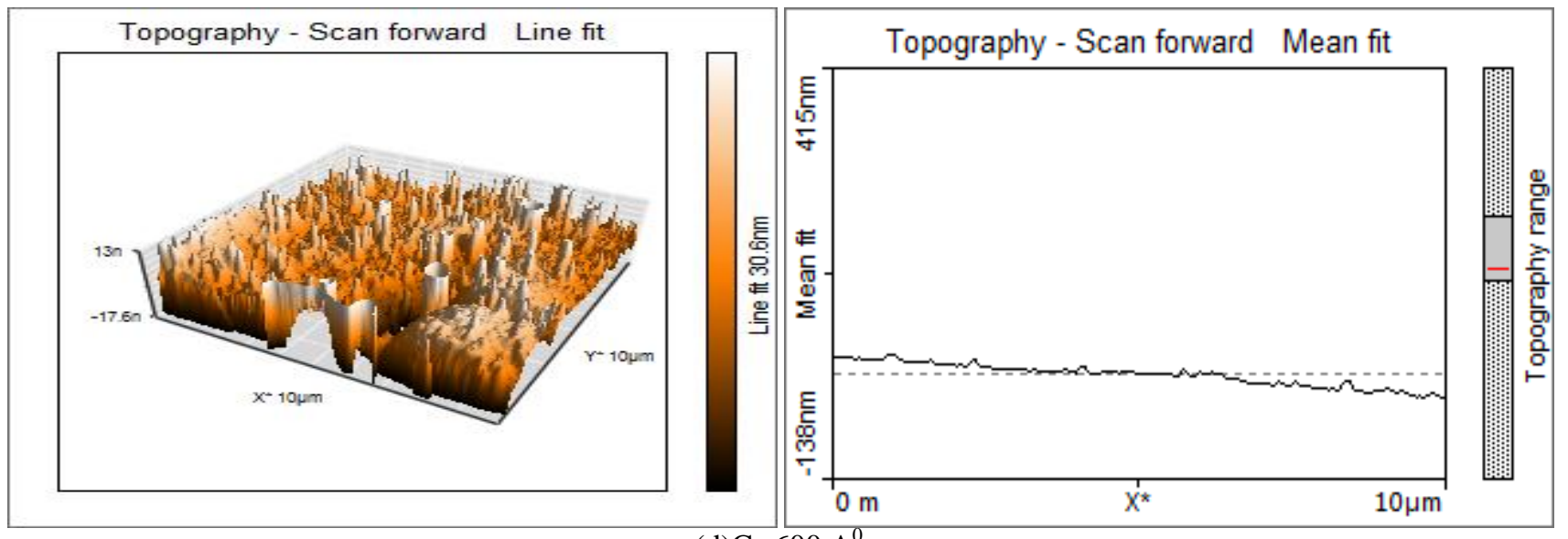

(d) $\mathrm{Cr}-600 \mathrm{~A}^{0}$ 


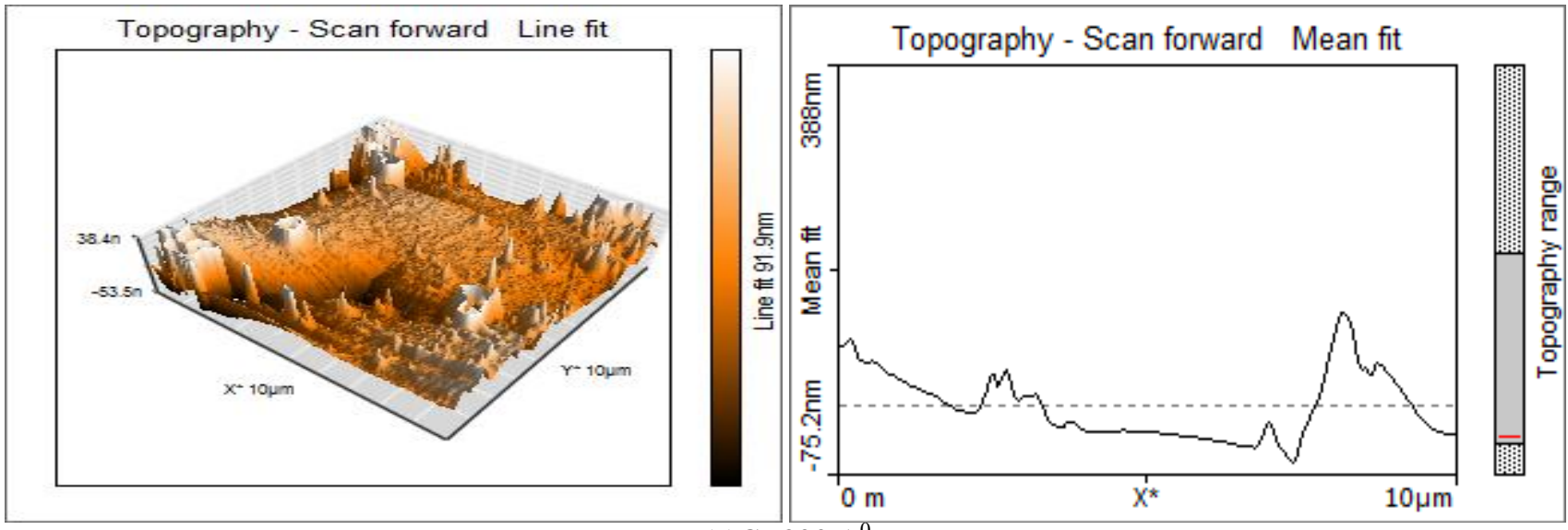

(e)Cr-800 A

Fig.2.AFM Pictures and Topography of Chromium films (a) $100 \mathrm{~A}^{0}$, (b) $200 \mathrm{~A}^{0}$, (c) $400 \mathrm{~A}^{0}$, (d) $600 \mathrm{~A}^{0}$, \&(e) $800 \mathrm{~A}^{0}$.

Fig.3 displays some images of chromium thin films recorded at different thicknesses. The grain growth are clearly noticed from the SEM images of the chromium films. It is observed that the surface morphology is almost smooth and grains are observed. It is clear from the SEM pictures the grain size increases with the increase in the film thickness as shown in

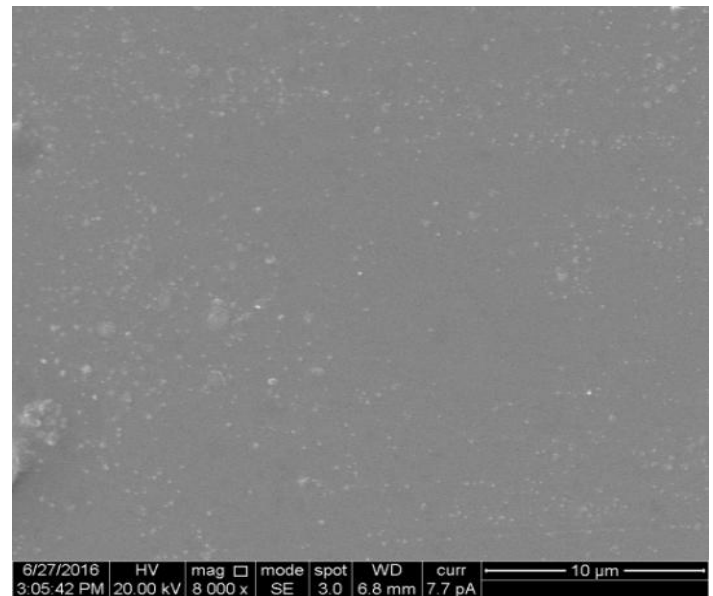

(a)Cr-200 A $\mathrm{A}^{0}$, mag X 8000

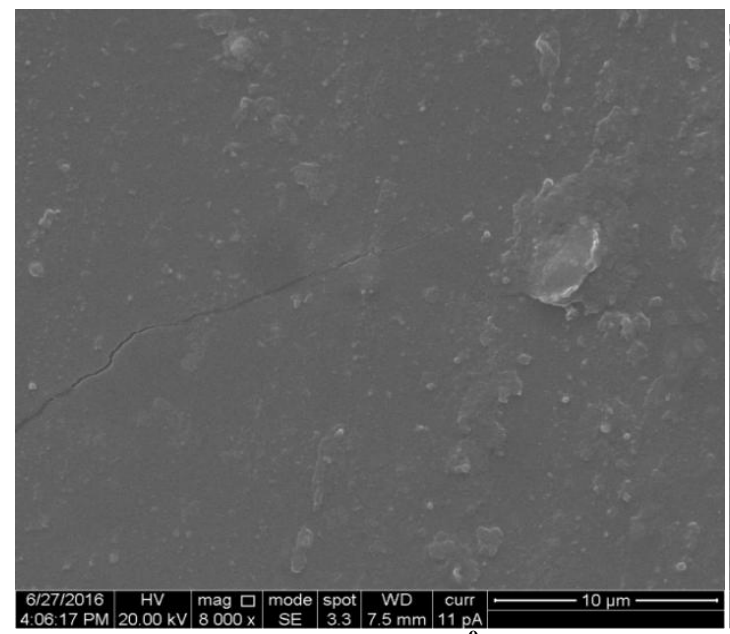

(c) Cr-600 A ${ }^{0}$,mag X 8000 the figure 3. (a), (b), \&(c). It is noticed that the film surface is pin-hole free texture without any micro-cracks. With the further increase in the thickness, cracks are developed in the film, creating oxide layer along the edges of the crack as shown in the fig 3(d).Similar types of structures have been reported for $\mathrm{cds}^{(11,12)}$.

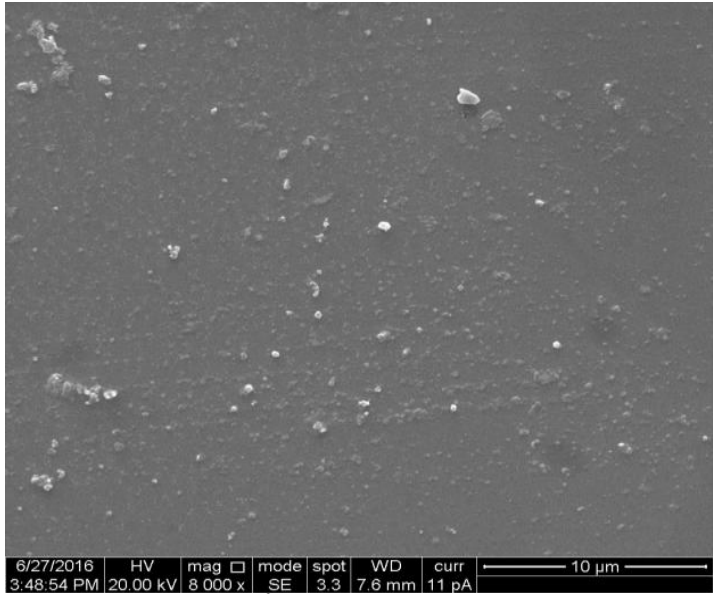

(b)Cr-400 A $\mathrm{A}^{\mathbf{0}}$, mag X 8000

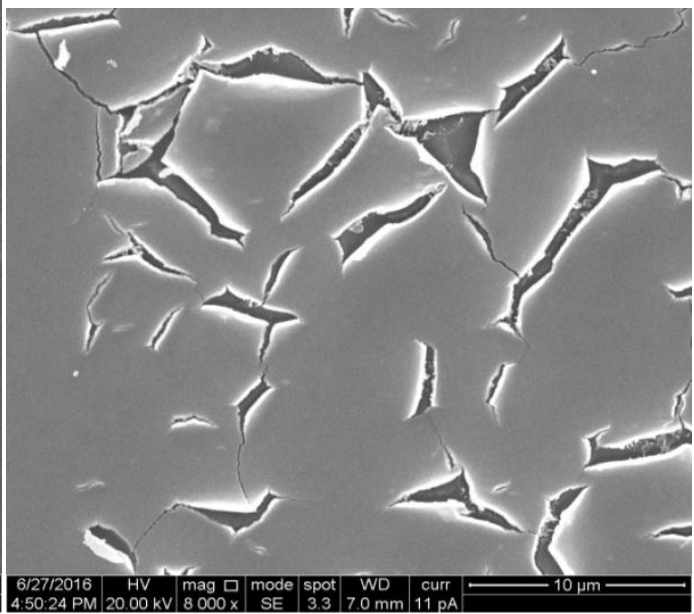

(d)Cr-800 A ${ }^{0}$, mag X 8000

Fig.3 SEM Pictures of thin chromium films 


\section{EDS ANALYSIS}

This is one of the powerful and useful forms of elemental analysis. It provides elemental information about the composition of the structure of the surface of a sample. It relies on an interaction of some source of X-ray excitation and thesample. Its characterization capabilities are due in large part to the fundamental principle that each element has a unique atomic structure allowing a unique set of peaks on its electromagnetic emission. Fig. 4 shows the EDS spectrum of chromium which confirms the material used in the present investigation is chromium as shown by multiple peaks. Similar graphs and peaks have been reported by G. N. Chavan et.al.[13] for Nickel substituted Cadmium Ferrites and H L Pushpalatha ${ }^{1}$ et.al.[14] for CdS thin film. The EDS spectrum displays the characteristic prominent peak indicating that the material utilized in the present investigation is chromium. Since the chromium films are deposited on glass substrates.

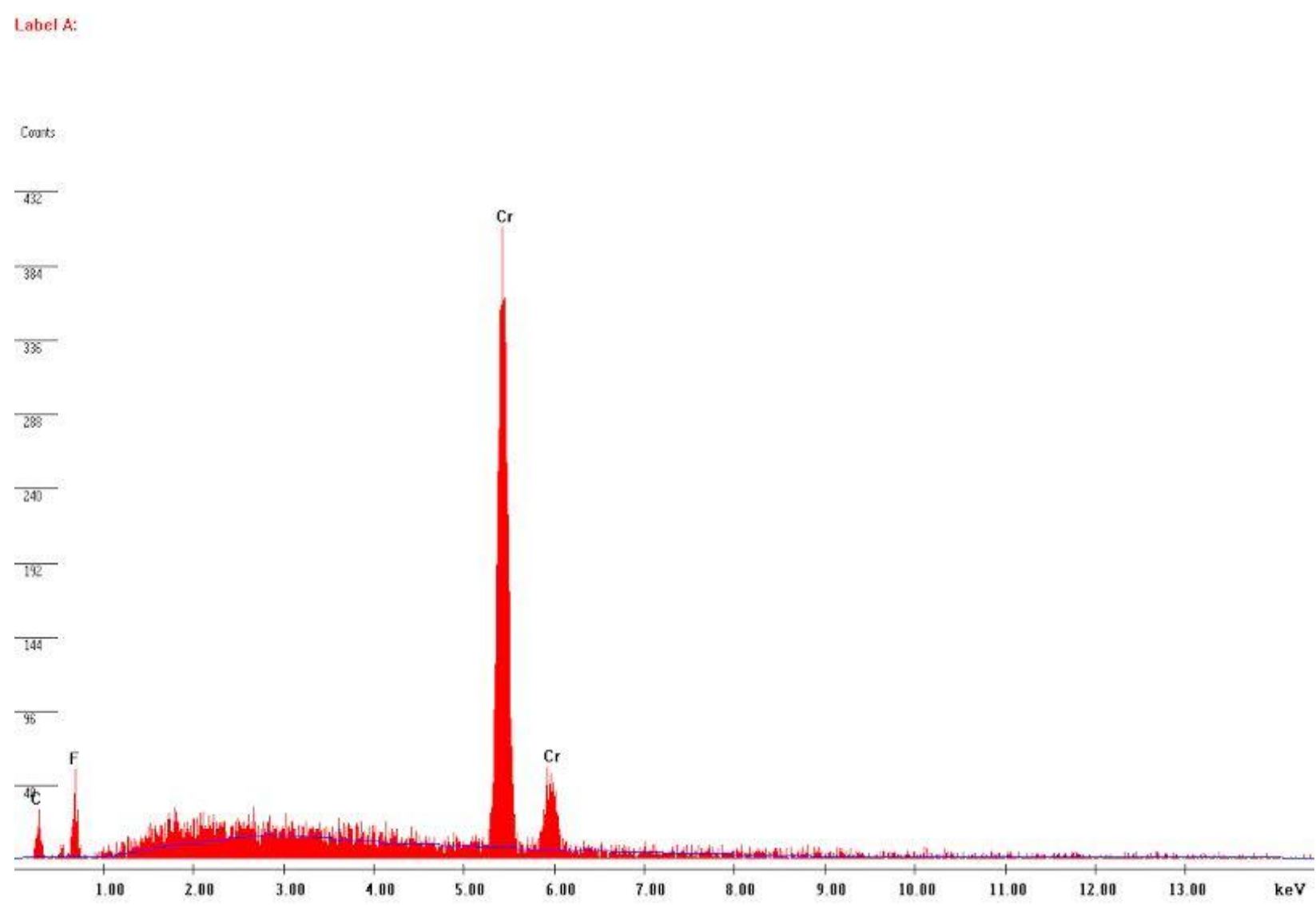

Fig 4: $\mathrm{Cr}-800 \mathrm{~A}^{0}$, EDS spectrum of chromium.

The $\mathrm{Y}$-axis shows the counts (number of X-rays received and processed by the detector) and the $\mathrm{X}$-axis shows the energy level of those counts.

\section{CONCLUSION}

We have analyzed the thickness dependence of microstructure of thin chromium films in the thickness range $100-800 \mathrm{~A}^{0}$. The structure of the microstructure is found to depend upon the thickness. The microstructure has been analyzed by four techniques using TEM, AFM, SEM \& EDS studies. The microstructure is dictated by the environment in which the film has been grown and the sticking coefficient of chromium with glass substrate. It is planned to carry out the similar experiment for silver films which will be communicated shortly.

\section{ACKNOWLEDGEMENT}

One of the authors Udachan L. A ${ }^{\mathrm{a}}$ is very much thankful to Mr.C.S.Gandigudi, V.G.Women's College, Kalaburagi, Karnataka, India for constant support and encouragement. 


\section{REFERENCES}

[1]. M.A.Angadi and L.A. Udachan, Thin Solid Films, 8, 1981, pp.299-302.

[2]. M.A.Angadi and L.A.Udachan, Journal of Materials Science, 16, 1981, 1412-1415.

[3]. SiadAhcene et.al. 17 th French-Polish Seminar ,"Reactivity of Solids", Dijon, France, June 2015, //www.researchgate.net/publication/283449988.

[4]. Kawagoe $\mathrm{T}$ and Mizoguchi T ,Jpn. J. Appl. Phys.32,1993, 935.

[5]. Li H-T, Jiang B-L and yang B, Appl. Surf. Sci. 258, 2011, 935 .

[6]. Foroughi-Abari A, Xu C and Cadien K C , Thin Solid Films, 520, 2012, 1762.

[7]. R. A. Andrievskii and A. M. Glezer, Phys. Met. Metallogr. 89, 2000, 83-102.

[8]. Maissel, L.I., "Hand Book of Thin Film Technology", Edited by Maissel L.I. and Glang, R., McGraw Hill, New York, 1970, pp.(e) 17-18.

[9]. Neugebauer, C.A.and Webb, R.W., Journal of Applied Physics, 33, 1962, pp.74.

[10]. T M Rajakumar et.al. Indian Journal of Pure \& Applied Physics, 51 , Feb. 2013, pp.131-137.

[11]. Be Xuan Hop et.al, VNU Journal of Science, Mathematics - Physics, 24, 2008, 119-123.

[12]. Munikrishna Reddy Y et.al, IOSR Journal of Applied Physics (IOSR-JAP) e-ISSN: 2278-4861, 4, Issue 4 (Sep. Oct. 2013), PP 01-07.

[13]. G. N. Chavan et.al. INTERNATIONAL JOURNALOF SCIENTIFIC \& TECHNOLOGY RESEARCH , 2, ISSUE 12, DEC. 2013, ISSN 2277-8616.

[14]. H L Pushpalatha et.al. Indian Journal of Applied Physics, 52, Aug. 2014, pp. 545-549. 